\title{
COMPLEXO PORTUÁRIO, RESERVA EXTRATIVISTA E DESENVOLVIMENTO NO MARANHÃO
}

\author{
Horácio Antunes de Sant’Ana Júnior*
}

\begin{abstract}
Em São Luís (MA), projetos de desenvolvimento implicam ampliação do Complexo Portuário e conflitos com comunidades tradicionais que demandam a legalização da Reserva Extrativista de Tauá-Mirim. Confrontam-se lógicas diferenciadas de ocupação territorial e de concepções da natureza, em um conflito ambiental que toma novos contornos com projetos de ampliação de equipamentos de infraestrutura e industriais, além de modificações na legislação urbanística do município. Assim, o objetivo aqui é analisar como concepções de desenvolvimento que orientam os vários agentes provocam consequências sociais e ambientais e se desdobram em situações conflitivas. Parte-se de trabalho de pesquisa efetivado por dez anos, através de levantamento bibliográfico, realização de entrevistas, conversas informais, acompanhamento de reuniões, assembleias, audiências públicas e manifestações públicas. A lógica de ocupação e uso do espaço que tem orientado planejadores e agentes de desenvolvimento estatais e privados em São Luís desqualifica modos de vida de comunidades rurais cujas principais lideranças, na busca de manter seu território, acionam repertórios de luta e constroem mecanismos de enfrentamento.
\end{abstract}

Palavras-chave: Conflitos ambientais. Projetos de desenvolvimento. Complexo Portuário de São Luís. Reserva Extrativista de Tauá-Mirim. Legislação urbanística.

\section{PARA COMEÇAR: introdução ao campo de pesquisa}

Entender a situação atual de comunidades tradicionais ${ }^{1}$ que demandam a oficialização da Reserva Extrativista de Tauá-Mirim, ${ }^{2}$ localizadas nas proximidades do Complexo Portuário ${ }^{3}$ de São Luís do Maranhão e seus prin-

* Universidade Federal do Maranhão. Programas de Pósgraduação em Ciências Sociais e Políticas Públicas.

Av. dos Portugueses, 1966. Campus do Bacanga. Cep: 65085580. Bacanga - São Luís - Maranhão - Brasil.

horacioantunes@uol.com.br

${ }^{1}$ Como este artigo trata de grupos sociais que atuam no sentido da instalação oficial de uma Reserva Extrativista, utilizaremos o conceito normativo estabelecido pelo Decreto Federal $n^{\circ}$ 6.040, de 07 de fevereiro de 2007: "Povos e Comunidades Tradicionais: grupos culturalmente diferenciados e que se reconhecem como tais, que possuem formas próprias de organizacãa social, que ocupam e usam territórios e recursos naturais como condição para sua reprodução cultural, social, religiosa, ancestral e econômica, utilizando conhecimentos, inovações e práticas gerados e transmitidos pela tradição" (BRASIL, 2007).

${ }^{2}$ Reservas Extrativistas (Resex) constituem uma modalidade de Unidade de Conservação (UC) prevista na legislação ambiental brasileira através da Lei Federal No 9.985, de 18 de julho de 2000, que instituiu o Sistema Nacional de Unidades de Conservação (SNUC). As Resex constituem o grupo de Unidades de Conservação de Uso Sustentável, cujo objetivo é "compatibilizar a conservação da natureza com o uso sustentável de parcela dos seus recursos naturais".

${ }^{3}$ O Complexo Portuário de São Luís é composto por um conjunto de portos públicos e privados: Porto da Alumar (de propriedade do Consórcio Alumínio do Maranhão, formado pelas empresas Alcoa, BHP Billiton e RioTintoAl- cipais dilemas e conflitos implica fazer uma apresentação geral do município de São Luís e, a partir de um necessário retorno ao processo de implantação de políticas desenvolvimentistas na década de 1960 no Maranhão e na Amazônia oriental brasileira, entender como essas políticas provocaram alterações na geografia local e resultaram em conflitos envolvendo o Estado, empreendedores privados, comunidades tradicionais e outros agentes sociais.

São Luís é a capital do estado brasileiro do Maranhão e fica localizada em uma grande ilha, que tem a denominação oficial de ilha do Maranhão, mas é também conhecida como ilha de São Luís, ou pelo nome utilizado pelo povo tupinambá, que tinha povoamentos na ilha antes da chegada dos colonizadores no início do sec. XVII: Upaon-Açu, que significa ilha Grande. A grande ilha, hoje, é composta por quatro municípios: São Luís, São José do Ribamar, Paço do Lumiar e Raposa. Fica localizada no Golfão

can), Terminal Marítimo da Ponta da Madeira (de propriedade da Vale S. A.) e pelo Complexo do Itaqui, formado por Porto do Itaqui, Terminal Pesqueiro do Porto Grande, Terminal da Ponta da Espera, Terminal do Cujupe e Terminal de São José de Ribamar. É administrado pela Empresa Maranhense de Administração Portuária (EMAP) (Moreira, 2015). 
Maranhense, entre as grandes baías de São Marcos e de São José. O ano oficial de fundação da cidade de São Luís é 1612 e, segundo dados do Instituto Brasileiro de Geografia e Estatística (IBGE, 2010), o município contava, em 2010, com uma população de 1.014.837 habitantes.

Duas características importantes da baía de São Marcos, em cujas margens está localizado o município de São Luís, são acionadas discursivamente por diferentes agentes sociais, quando envolvidos em debates sobre as formas mais adequadas de sua ocupação e do uso territorial. De um lado, recorre-se ao argumento de que essa é uma baía de águas muito profundas, o que, desde o período colonial, tornou-a desejável para instalação de grandes portos, pois permite a atracação de navios de grande calado, oferecendo condições para o transporte internacional de alta escala. De outro lado, devido ao fato de ser estuário de grandes rios - como o Mearim, o Grajaú, o Pindaré - e devido à presença significativa de manguezais (ecossistema privilegiado para a reprodução de peixes e mariscos), a baía de São Marcos, para o caso aqui estudado, especialmente na porção sudoeste da ilha do Maranhão, foi historicamente percebida como bastante piscosa, propiciando a fixação de comunidades de pescadores em suas margens.

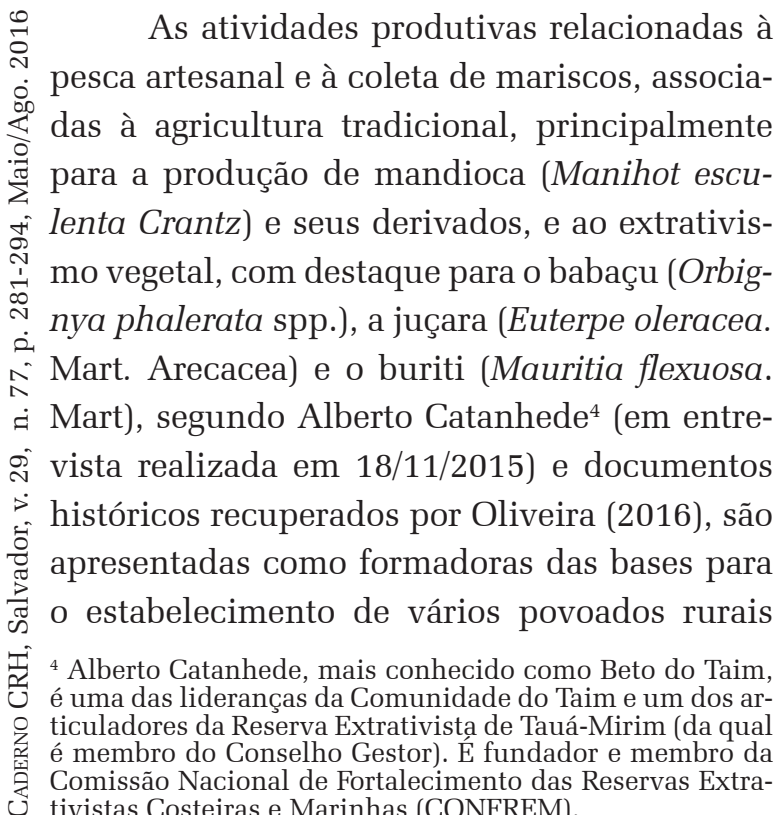

desde o século XVIII, os quais, a partir de inúmeras formas de relacionamento entre si, conformaram um grande território tradicional.

São Luís, por ser a capital do Estado do Maranhão e por ter se constituído como centro comercial associado à navegação, era o alvo principal da comercialização da parte da produção pesqueira, extrativista ou agrícola não consumida ou trocada entre as comunidades localizadas no sudoeste da ilha. Assim, até o início da década de 1980, o fato de ser uma cidade portuária, permitindo a existência de um mercado consumidor para produtos das comunidades, era também um motivo de atração para pescadores de outras regiões do estado e para a constituição e afirmação do modo de vida (Cândido, 1975) local.

A presença de portos associados à comercialização internacional na baia de São Marcos data do início do século XVII, com os primeiros passos da colonização europeia no litoral norte do Brasil. Contudo, a partir dos anos 1970, com os projetos de integração da Amazônia brasileira às dinâmicas econômicas da expansão capitalista no Brasil, implementada a partir de macroplanejamentos realizados pelo Governo Federal, novos e grandes portos são construídos ou planejados na região sudoeste da ilha. A construção desses portos, da infraestrutura a eles associada (ferrovias e terminais ferroviários, rodovias, terminais de tancagem, armazéns, pátios de descarga de minérios etc.) e de várias plantas industriais implicou a desapropriação de grande número de comunidade rurais e de pescadores e no consequente deslocamento compulsório de seus moradores. Operamos, aqui, com as definições de deslocamento compulsório de Magalhães (2007, p. 14), segundo a qual esse é

o processo pelo qual determinados grupos sociais, em circunstâncias sobre as quais não dispõem de poder de deliberação, são obrigados a deixar ou a transferir-se de suas casas e/ou de suas terras. Há, portanto, um conteúdo de cerceamento do poder decisório no interior do próprio grupo social, advindo de uma intervenção externa; 
e de Almeida (1996, p. 30), para quem se trata do

conjunto de realidades factuais em que pessoas, grupos domésticos, segmentos sociais e/ou etnias são obrigados a deixar suas moradias habituais, seus lugares históricos de ocupação imemorial ou datada, mediante constrangimentos, inclusive físicos, sem qualquer opção de se contrapor e reverter os efeitos de tal decisão, ditada por interesses circunstancialmente mais poderosos.

A experiência social resultante desses processos de deslocamento refletiu também nas comunidades que não foram deslocadas. O conjunto de comunidades do sudoeste de Upaon-Açu constituiu, historicamente, um grande território tradicional, com relações de amizade, de parentesco e de compadrio, troca de produtos, compartilhamento de atividades festivas, religiosas e culturais. Assim, os deslocamentos de algumas comunidades desestabilizaram essas relações e geraram a percepção de que novos deslocamentos, com todas suas consequências, seriam possíveis a qualquer momento. Para algumas das lideranças locais, reunidas, principalmente, nas Comunidades Eclesiais de Base (CEBs) da Igreja Católica (Alves, 2014), foi se configurando a necessidade de buscar instrumento de garantia de controle e uso de seus territórios, incluindo os locais de moradia, das atividades agrícolas, do extrativismo vegetal, da pesca e da coleta de mariscos.

Os processos recentes de tentativa expansão portuária, das atividades industriais e de outros equipamentos de infraestrutura, associados com o projeto de revisão do Plano Diretor de São Luís e da Lei de Zoneamento, Parcelamento, Uso e Ocupação do Solo promovido pela Prefeitura Municipal de São Luís, são orientados por uma específica noção de desenvolvimento, que não considera os modos de vida locais e opera com a possibilidade de deslocamento populacional. Esses processos têm de se defrontado com formas de resistência local que, na busca de garantia do controle de territórios e desafiando a noção dominante de desenvolvimento, encontraram, na demanda pela instalação de Reserva Extrativista de Tauá-Mirim, um instrumento legal de defesa do que as lideranças locais consideram ser seus direitos territoriais. O escopo da luta por esses direitos territoriais é ampliado na medida em que tais direitos são associados à defesa de direitos ambientais, provocando o que José Sérgio Leite Lopes (2006) denomina de ambientalização dos conflitos sociais.

O principal objetivo deste artigo é analisar como concepções de desenvolvimento que orientam vários agentes diferenciados provocam consequências sociais e ambientais no sudoeste da ilha de Upaon-Açu e se desdobram em situações conflitivas, que, por seus componentes relacionados a modos de vida tradicionais e à conservação da natureza, podem ser classificados como conflitos ambientais. Para tanto, adotaremos a concepção de conflitos ambientais de Henri Acselrad (2004, p. 26), segundo a qual

conflitos ambientais são aqueles envolvendo grupos
sociais com modos diferenciados de apropriação,
uso e significação do território, tendo origem quando
pelo menos um dos grupos tem a continuidade das
formas sociais de apropriação do meio que desen-
volvem ameaçada por impactos indesejáveis - trans-
mitidos pelo solo, água, ar ou sistemas vivos - de-
correntes do exercício das práticas de outros grupos.

O artigo é fruto de trabalho de pesquisa realizado durante dez anos no âmbito do Grupo de Estudos: Desenvolvimento, Modernidade e Meio Ambiente da Universidade Federal do Maranhão (GEDMMA/UFMA). ${ }^{5}$ Para tanto, vem sendo feito levantamento bibliográfico que envolve temas como desenvolvimento, projetos de desenvolvimento, conflitos ambientais, atividades portuárias, deslocamen-

${ }^{5}$ Atualmente, essa pesquisa está sendo realizada através do projeto "Conflitos Ambientais no Maranhão", financiado pelo Conselho Nacional de Desenvolvimento Científico e Tecnológico (CNPq), através da Chamada Universal 14/2013, e pela Fundação de Amparo à Pesquisa ao Desenvolvimento Científico e Tecnológico do Maranhão (FAPEMA), através do edital FAPEMA $n^{\circ}$ 01/2014 Universal e através de Bolsa de Estímulo à Produtividade em Pesquisa - Edital FAPEMA No 10/2015 BEPP. Agradecemos a essas agências de fomento pelo fundamental apoio. 
tos compulsórios, povos e comunidade tradicionais, unidades de conservação e legislação ambiental brasileira. As informações empíricas foram obtidas através de: entrevistas com lideranças das comunidades, militantes de movimentos sociais e agentes governamentais; conversas informais com agentes envolvidos nos conflitos; trabalho de campo, envolvendo registro no caderno de campo; acompanhamento de reuniões, assembleias, audiências públicas, manifestações públicas. São arregimentadas, também, informações obtidas em trabalhos de orientação de teses de doutorado, dissertações de mestrado, trabalhos de conclusão de cursos de graduação e relatórios de iniciação científica.

\section{PROGRAMA GRANDE CARAJÁS E COMPLEXO PORTUÁRIO DE SÃO Luís}

No início dos anos 1960, foram divulgadas notícias sobre grandes jazidas de minério de ferro no sudeste do Pará, estado vizinho do Maranhão. Para garantir a exploração e a exportação do minério de ferro dessas jazidas, a então estatal Companhia Vale do Rio Doce, hoje privatizada e autodenominada Vale S. A., criou o Projeto Ferro Carajás (PFC), que tinha como espinha dorsal um sistema que pode ser definido como mina-ferrovia-porto (Carneiro, 1997; Monteiro, 1997). As minas, localizadas no município de Parauapebas, seriam ligadas à região portuária através de uma ferrovia. As características do litoral de São Luís (profundidade das águas, proximidade com os mercados 2. estadunidense, europeu e asiático, através do - Canal do Panamá, que permite o acesso entre j os oceanos Atlântico e Pacífico) foram acionadas como argumentos para sua escolha como espaço de instalação privilegiada de portos exportadores do minério.

Como decorrência dessa escolha, foi construída a Estrada de Ferro Carajás (EFC), com 892 km, saindo do sudeste do Pará e cruzando toda a região oeste do Maranhão até al- cançar à zona portuária de São Luís. A construção da ferrovia foi iniciada nos finais dos anos 1970, e sua primeira carga foi transportada no ano de 1985 (Alves, 2014). Inicialmente, a carga de minérios foi exportada pelo Porto do Itaqui, que funcionava desde 1974 (Moreira, 2015), mas, já em 1986, a Companhia Vale do Rio Doce iniciou a construção do Terminal Marítimo da Ponta da Madeira (Moreira, 2015), completando o seu sistema mina-ferrovia-porto.

Como decorrência do Projeto Ferro Carajás e compondo o macroplanejamento de caráter desenvolvimentista elaborado pelo Governo Federal através dos Planos de Integração Nacional (Sant'Ana Júnior, 2004), em pleno regime ditatorial iniciado com o golpe de 1964, foi concebido o Programa Grande Carajás (PGC) que, para além de um projeto de exploração minerária, constituiu-se em um programa de desenvolvimento regional que coordenava a ação de vários ministérios e visava a atuação em projetos minero-metalúrgicos, agropecuários, florestais e de infraestrutura (ferrovias, rodovias, portos e barragens). O PGC foi institucionalizado pelo Presidente da República, João Figueiredo, através Decreto Lei 1813, de 24 de novembro de 1980, com o objetivo de dinamizar economicamente a Amazônia oriental brasileira, abrangendo uma área de aproximadamente $900.000 \mathrm{~km}^{2}$, envolvendo partes dos estados do Pará, Goiás, hoje estado do Tocantins, e Maranhão. Com a efetivação do PGC, a ferrovia e os portos não seriam utilizados somente para o transporte de minério de ferro, mas teriam suas funções otimizadas economicamente com o transporte de produtos do agronegócio, da exploração florestal, das siderúrgicas que iriam se instalando ao longo da ferrovia e de outras atividades minerárias.

Alves, Sant'Ana Júnior e Mendonça (2007, p. 31) lembram que o

Programa Grande Carajás surgiu a partir das investidas do regime ditatorial, instalado a partir de 1964, no sentido da industrialização e, consequente modernização do país e que previa, concomitante e associadamente, a integração da Amazônia à dinâmica 
econômica do país [...] O Governo Federal planejou a instalação de infraestrutura básica (construção de grandes estradas de rodagem que cruzassem toda a região, algumas ferrovias, portos, aeroportos, usinas hidroelétricas) que permitisse a rápida ocupação da região, entendida, então, como um grande vazio demográfico e, poderíamos falar mesmo, como um 'vazio cultural'. A integração à economia nacional e internacional dar-se-ia principalmente através da instalação de grandes projetos de desenvolvimento destinados à exploração mineral, florestal, agrícola e pecuária.

Tendo sido escolhido como local de instalação da estrutura portuária vinculada ao Programa Grande Carajás, o município de São Luís passou a conviver com suas consequências diretas. Uma dessas consequências foi a instalação de dois grandes empreendimentos: a Companhia Vale do Rio Doce, com seus terminais ferroviários e portuários, e uma usina de produção de ferro gusa, que se constitui na primeira e mais poluente etapa da produção do aço; e o Consórcio Alumínio do Maranhão (Alumar), com seu porto e uma planta industrial que constitui "um dos maiores complexos de produção de alumínio primário e alumina do mundo" (Alumar, 2016). Para instalação desses empreendimentos, cerca de 10.000 hectares foram desapropriados e cedidos pelo governo estatual para a Alumar e cerca de 4.000 hectares foram cedidos para a Companhia Vale do Rio Doce. Frans Gistelink (1988), Ann Bárbara Eglish (1984) e Madeleine Cousineau Adriance (1996) e, mais recentemente, Elio de Jesus Pantoja Alves (2014) descrevem as inúmeras situações de deslocamentos compulsórios de povoados rurais secularmente presentes nas áreas que foram destinadas a essas empresas. Esses deslocamentos provocaram a desestabilização de relações existentes no território mais amplo.

Alberto Catanhede Lopes, o Beto do Taim, ${ }^{6}$ em entrevista a Ana Carolina Pires Miranda, Maiâna Roque da Silva Maia e Rafael Bezerra Gaspar (2009, p. 203), lembra que

${ }^{6}$ (Ver nota 4). nós tínhamos uma relação com as comunidades de lá (área em que foi implantada a Alumar), que elas eram muito mais agricultoras que nós daqui. Nós, desse lado, éramos muito mais pescadores [...] quando era tempo de fazer farinha, eles não tinham tempo nem para ir na beira do rio pescar [...] Então, nós sortíamos eles de peixe e eles traziam farinha. Além de que, como a área deles lá era maior, sempre foi maior, a gente ia lá buscar a palha, o cipó para construção das casas aqui. Com a implantação da Alcoa, várias pessoas aqui foram presas por tentar fazer isso; então, foi um outro recurso que a gente perdeu, a relação que a gente tinha com o outro lado do rio, com as comunidades de lá, Carnaúba, Pindotiua, Paquatiua. Essas comunidades lá, depois do igarapé, a gente tinha essa relação muito estreita com eles[...]

Alves (2014) descreve também situações de resistência e enfretamento que garantiram que algumas comunidades não fossem deslocadas. No início dos anos 1980, foi constituído o Comitê de Defesa da Ilha, que assumiu como tarefa a contestação da instalação do Consórcio Alumar e que, envolvendo intelectuais, profissionais liberais, professores, artistas, religiosos e poetas, apoiou as comunidades que resistiam e, apesar de não ter conseguido frustrar a construção da indústria de alumínio, propiciou o acúmulo de experiências nesse tipo de mobilização.

Paralelamente às iniciativas de instalação de grandes projetos de desenvolvimento na ilha, houve tentativas de sucessivos governos estaduais no sentido de instalação do Distrito Industrial de São Luís (DISAL). Segundo Ayres (1990, p. 157) a "idéia de implantação de um distrito industrial em São Luís surgiu quando da divulgação do potencial de minério de ferro da Serra dos Carajás, no Pará, e, da possibilidade do escoamento desse minério pelo Porto do Itaqui”. Essa ideia se concretizou com iniciativas do governo estadual que estavam sintonizadas com Programa Grande Carajás. Carvalho $(2011$, p.) aponta que

É nesse contexto que surge o Distrito Industrial de São Luís (DISAL) que tem seu primeiro traçado baseado no Decreto Estadual no 3.589, de 28 de novembro de 1974, que delimitava a área industrial do Itaqui-Ba- 
canga. Posteriormente, o Decreto Estadual $n^{\circ} 3.840$, de 22 de abril de 1977, determina como industrial a área do Tibiri-Pedrinhas, acrescentando outro território ao perímetro. A obrigatória adequação do DISAL à legislação ambiental, com as áreas Itaqui-Bacanga e Tibiri-Pedrinhas unificadas, resultou na formulação do Decreto Estadual n ${ }^{\circ}$ 7.632, de 23 de maio de 1980, que declarava que o Distrito Industrial de São Luís obtinha uma área de 19.946, 2316 ha.

O PGC, por sua vez, foi extinto oficialmente em 1991, dentro do processo de enxugamento da máquina pública realizado pelo governo Fernando Collor, ${ }^{7}$ a partir da orientação neoliberal que se implantava no país (Sant'Ana Júnior, 2013). Porém, mesmo após sua extinção, como instância oficial, o PGC continuou exercendo forte influência na sua região de abrangência.

A Prefeitura Municipal de São Luís, no entanto, no ano de 1992, aprovou a Lei Municipal $\mathrm{n}^{\circ} 3.253$, que estabelecia o zoneamento, parcelamento, ocupação e uso do solo no município. Segundo lembra Carvalho (2011), essa lei mantinha como zona rural boa parte dos territórios que haviam sido decretados como integrantes do DISAL. Essa divergência legal tomou proporções mais acentuadas quando, em 2001, o Governo Federal aprovou o Estatuto da Cidade (Lei Federal $n^{\circ}$ 10.257), que passou a considerar o município como principal : $\dot{\circ}$ urbanístico. Com isso, a Lei de Zoneamento municipal passou a ser um dos principais obstáculos para a plena instalação do DISAL (Carvalho, 2011).

Este debate tornou-se uma questão pú¿. blica quando, no ano de 2004, foram anuncia$\hat{\AA}$ dos publicamente os planos de instalação de \&. um polo siderúrgico que envolveria a construSે ção de cinco grandes usinas siderúrgicas (três

을 ${ }^{7}$ Fernando Collor de Melo foi o primeiro presidente do Brasil eleito por voto direto após a ditadura de 1964 a స్ 1985. Sua eleição ocorreu em 1989, e seu mandato foi de . 1990 a 1992, quando renunciou ao cargo em funcão de um ב processo de impeachment, mediante acusações de corrup-

کु ção. Desde o processo eleitoral, assumiu uma campanha

de franca defesa de reformas de orientação neoliberal na economia brasileira. A extinção do Programa Grande Carajás fez parte de seu projeto de enxugamento da adminisษ tração federal. de produção de placas de aço e duas de produção de ferro gusa) nas imediações do Complexo Portuário de São Luís. Sant’Ana Júnior e colaboradores (2009, p. 30) afirmam que

\begin{abstract}
No projeto original do pólo, a área destinada às instalações físicas das usinas seria de 2.471,71 hectares, localizados entre o Porto do Itaqui e o Rio dos Cachorros, na região administrativa municipal do Itaqui/Bacanga. Em 2004, esta área foi declarada como de utilidade pública para fins de desapropriação pelo governo do Estado do Maranhão (Decretos $n^{\circ}$ 20.727-DO, de 30/08/2004, e no 20.781-DO, de 29/09/2004), o que implicaria no deslocamento compulsório de seus moradores e/ou daqueles que a utilizam de forma produtiva. Estes moradores são estimados em mais de 14.400 pessoas distribuídas em doze povoados (Vila Maranhão, Taim, Cajueiro, Rio dos Cachorros, Porto Grande, Limoeiro, São Benedito, Vila Conceição, Anandiba, Parnuaçu, Camboa dos Frades e Vila Madureira).
\end{abstract}

Os discursos de defesa da instalação do polo eram realizados tomando a necessidade de desenvolvimento econômico do Maranhão como principal argumento. A geração de empregos, as perspectivas de utilização de novas tecnologias e novas demandas de preparação de mão de obra, a ampliação de cursos técnicos e universitários eram apontados como os principais ganhos para a região.

Parte dos moradores dos povoados ameaçados de deslocamento, porém, reagiu muito fortemente à instalação polo siderúrgico e buscou acionar instrumentos de resistência. Alves (2014), com base na noção de "repertório de contestação" de Tilly (1978; 1996), que remete à construção de argumentos para a contestação de um projeto, afirma que lideranças locais, informadas pela participação nos processos de resistência dos anos 1980, em especial aqueles capitaneados pelo Comitê de Defesa da Ilha, acionaram repertórios de mobilização, buscando estabelecer processos de arregimentação dos moradores e de construção de alianças com movimentos sociais e personalidades com atuação na cidade. Dessa forma, foi constituído o Movimento Reage São Luís que, tal como o Comitê dos anos 1980, reunia moradores das 
comunidades, profissionais liberais, sindicalistas, professores, estudantes e religiosos. Segundo Alves (2014, p. 16-17), tratava-se de uma

\begin{abstract}
reação política de atores locais em confronto com forças econômicas e políticas de agentes econômicos e políticos externos muito mais poderosos e com poder de manobra desproporcional ao dos habitantes daqueles pequenos 'povoados rurais'. Entre estes agentes externos estão, para citar apenas os principais, a Companhia Vale, em parceria com a maior siderúrgica chinesa, a Baosteel Shanghai Group Corporation, além de empresas como a siderúrgica francesa Arcelor, a sul-coreana Pohang Steel Company-Posco, a alemã Thyssen Krupp, até então em processo de negociação, além do próprio governo brasileiro, interessado na viabilidade do projeto.
\end{abstract}

Pode-se acrescentar, além desses agentes, o decidido posicionamento dos governos estatual de Maranhão e municipal de São Luís (Sant'Ana Júnior et al., 2009).

No enfrentamento ao projeto, o Movimento Reage São Luís conseguiu reunir mobilização popular com expertise técnica, advinda de várias áreas do conhecimento, o que possibilitou ampliar o repertório de contestação ao projeto de instalação do polo siderúrgico. Numa tentativa de eliminar entraves legais à instalação do polo siderúrgico e de compatibilizar a legislação municipal com as leis estaduais que criaram o DISAL, a prefeitura municipal de São Luís encaminhou um projeto de lei à Câmara Municipal que tinha por objetivo alterar parte da Lei de Zoneamento, Parcelamento, Uso e Ocupação do Solo, convertendo os 2.471,71 hectares almejados para construção do empreendimento de Zona Rural para Zona Industrial (Carvalho, 2009; Sousa, 2009). Nos anos de 2004 e 2005, ocorreu uma série de audiências públicas (a maior parte delas resultantes da intervenção do Ministério Público Federal e do Ministério Público do Maranhão, provocados pelo Movimento Reage São Luís), mobilizações e debates em jornais, que culminaram com a votação do projeto da Lei de Zoneamento na Câmara Municipal. Após intensos debates e mobilizações, atendendo, principalmente, a ar- gumentos de caráter ambiental, que apontavam para fragilidade ecossistêmica da ilha, para o alto consumo de água que o empreendimento iria requerer (numa ilha que tem mais de $50 \%$ do seu abastecimento vindo do continente), para o comprometimento da capacidade de recarga dos aquíferos e para o desmatamento de manguezais, a Câmara Municipal optou por converter apenas 1.068 hectares em Zona Industrial, o que seria insuficiente para atender ao projeto inicial. Somada a fatores externos (como a queda do preço internacional do aço), a decisão dos vereadores acabou influenciado decisivamente para o abandono do projeto de instalação do polo siderúrgico (Alves, 2014; Sant'Ana Júnior et al., 2009).

A frustração com relação à construção do polo siderúrgico, no entanto, não significou o abandono definitivo de projetos de ampliação da infraestrutura e de instalação de novos empreendimentos industriais e portuários nas áreas próximas aos grandes portos de São Luís. Os planejadores estaduais de sucessivos governos alteraram muito pouco a posição de defesa do desenvolvimento do Maranhão a partir do crescimento das atividades portuárias e de suas adjacências, numa perspectiva voltada, principalmente, para atender ao mercado de exportação. Assim, repetem-se discursos que defendem ter a área portuária de São Luís uma vocação industrial. Esses discursos são emitidos tanto por agentes estatais, como, por exemplo, no caso do documento "O Maranhão e a Nova Década: Oportunidade e Desafios”, que foi elaborado, em 2010, pela Secretaria Estadual de Planejamento para orientar o "desenvolvimento" do estado entre os anos de 2010 e 2020 (Maranhão, 2010), como por agentes empresariais, como, por exemplo, em notícias veiculadas no site da Associação Comercial do Maranhão, afirmando que "O Porto do Itaqui, o corredor de exportação Carajás deixam clara a vocação industrial daquela área. Dessa forma o tratamento não deve ser o de estímulo a atividade rural " (Carvalho, 2008, p. 56).

No ano de 2011, no interior da área que 
foi convertida em Zona Industrial pela Câmara Municipal em 2005, iniciou-se a instalação da Termelétrica Porto do Itaqui, pela empresa MPX. ${ }^{8}$ Para tanto, foi promovido mais um processo de deslocamento de comunidade. A comunidade de Vila Madureira, que já havia sido ameaçada pelo projeto do polo siderúrgico, foi, enfim, deslocada para o Residencial Nova Canãa, no município de Paço do Lumiar, que fica a $40 \mathrm{~km}$ de seu local de origem, distante do mar e a $6 \mathrm{~km}$ do campo agrícola que foi disponibilizado para os moradores (Sant'Ana Júnior; Pereira; Alves, 2010). A distância do mar é um fator importante, pois grande parte dos moradores era formada de pescadores. O campo agrícola, além de distante, apresenta características diferentes da agricultura tradicional anteriormente praticada. A Termelétrica Porto do Itaqui tem como principal combustível para produção de energia o carvão mineral importado da Colômbia. Esse é um tipo de produção de energia altamente poluente e tem provocado inúmeras queixas de moradores dos povoados vizinhos.

Além da termelétrica, nos últimos anos, a região próxima ao Complexo Portuário de São Luís tem convivido com uma intensa proliferação de empreendimentos industriais, como cimenteiras, fábricas de asfalto, indústrias de fertilizan: tes, além da ampliação de atividades minerárias, . principalmente relacionadas com a extração de $\underset{1}{4}$ areia e pedra para a construção civil.

\section{COMUNIDADES TRADICIONAIS E A LUTA PELA DEFESA DO TERRITÓ- RIO: a reserva extrativista entre a demanda, a criação e a legalização}

A discussão e a construção de formas de luta para garantir o controle do território por parte de um conjunto de comunidades próximas ao Complexo Portuário de São Luís acontecem desde a implantação desse Complexo e

${ }^{8}$ Atualmente, a empresa proprietária da Termelétrica mudou seu controle acionário e passou a chamar-se Eneva. de empreendimentos a ele associados. Dentre as formas de luta acionadas, destaca-se a demanda pela constituição da Reserva Extrativista de Tauá-Mirim, que hoje tem um perímetro que abarca doze comunidades: Taim, Rio dos Cachorros, Porto Grande, Limoeiro, parte do Cajueiro (Praia de Panauaçu), parte da Vila Maranhão (Porto das Arraias), Portinho, Jacamim, Ilha Pequena, Embaubal, Amapá e TauáMirim. Segundo D. Maria Máxima ${ }^{9}$ (entrevista realizada em 22/08/2014),

- Foi nas reuniões da Paróquia do Bonfim que nós
começamos a conversar sobre o que fazer para per-
manecer nos nossos lugares. Eu tenho uma missão
que foi dada por minha tia, que tinha o mesmo
nome meu, antes de morrer. Ela me disse que devia
continuar a luta pelo Rio dos Cachorros e não deixar
que tomassem as terras de nosso povo.

A Paróquia do Bonfim, vinculada à Igreja Católica, incentiva a formação de Comunidades Eclesiais de Base (CEBs) e, desde o Comitê de Defesa da Ilha, contou com religiosos e leigos que atuavam em defesa dos territórios. Alberto Catanhede, o Beto do Taim, em entrevista a Miranda, Maia e Gaspar (2009, p. 184), lembra que,

Para chegar na Reserva extrativista, não demorou muito tempo. Nós começamos a pensar nela meio pingada a discussão em 1996, e começamos a aprofundá-la em 1998. Mas começamos a aprofundá-la em 1998, nós já tínhamos, por exemplo, o Centro Nacional de Populações Tradicionais, o CNPT, que subsidiava muito essa discussão, a partir das Reservas do Acre, que nós nunca conseguimos ir lá, mas eles traziam essas informações nas discussões de Unidades de Conservação. Toda a assembleia do GTA (Grupo de Trabalho Amazônico), todas as assembleias do CNS (Conselho Nacional dos Seringueiros), todas as assembléias da COIABE (Coordenação das Organizações Indígenas da Amazônia Brasileira), que são os povos indígenas, todos esses grupos, todas as assembléias desses grupos incluía, na pauta, as Unidades de Conservação. Então, nós estávamos sempre nesses debates.

${ }^{9}$ Maria Máxima é moradora do Rio dos Cachorros, membro do Conselho Gestor da Resex, liderança e referência comunitária (como prefere ser chamada, no lugar de liderança), envolvida com a demanda pela Reserva Extrativista desde seu início. 
Na fala de Beto do Taim, é possível perceber que as lideranças locais, desde o final dos anos 1990, buscavam se articular com movimentos de caráter mais abrangente e traduzir, para sua realidade local, os debates dos quais participavam.

Assim, a busca de formas de garantia do controle territorial contra possíveis ameaças de agentes governamentais ou empresariais desembocou na proposta de demandar a constituição de uma reserva extrativista. Para Sant'Ana Júnior (2013), os entraves surgidos para a efetivação de uma ampla reforma agrária no Brasil, após a Constituição de 1988, provocaram a busca por outros instrumentos legais que garantissem a permanência, em seus territórios, principalmente de grupos sociais que, já tendo a posse, não possuíam regularização cartorial ou eram detentores de títulos de propriedade frágeis. Assim, vários grupos buscaram, na Constituição de 1988 ou na legislação dela derivada, mecanismos de garantia do território, como o reconhecimento de terra de quilombo, de terra indígena ou de povos e comunidades tradicionais.

Como fator que levou à demanda pela Reserva Extrativista de Tauá-Mirim, é importante destacar que, após a posse de Luís Inácio Lula da Silva na Presidência da República, em 2003, a Superintendência da Regional do Maranhão do Instituto Brasileiro do Meio Ambiente e dos Recursos Naturais Renováveis (Ibama) foi assumida por Marluze Pastor, ao mesmo tempo em que Kátia Barros assumia a direção local do Centro Nacional de Populações Tradicionais (CNPT), então vinculado ao IBAMA. Ambas tinham fortes vínculos com o movimento negro no Maranhão e muita proximidade com os moradores da zona rural de São Luís, em especial com moradores da comunidade do Taim. Essas aproximações foram decisivas para a veiculação de informações sobre reservas extrativistas e sobre os mecanismos de sua efetivação.

Marluze Pastor (entrevista realizada em 06/07/2010) lembra que havia um empenho efetivo do Ibama em promover a criação de reservas extrativistas, em especial em áreas em que conflitos ambientais estavam mais ativos. Segundo Kátia Barros (entrevista realizada em 02/06/2012), “O Maranhão é o estado que mais tem pedido de criação de unidades de conservação no modelo das reservas extrativistas". Até 2011, existiam dezenove pedidos de criação de Reservas Extrativista no Maranhão. Assim, em 2003, através de um abaixo-assinado que envolvia associações de moradores e lideranças de seis comunidades (Taim, Rio dos Cachorros, Limoeiro, Cajueiro, Porto Grande e Vila Maranhão), foi dada entrada na solicitação de criação de uma reserva extrativista no sudoeste da ilha do Maranhão, então com o nome de Reserva Extrativista do Taim.

O pedido foi acolhido em caráter de urgência pelo Ibama, pois, logo no ano seguinte, em 2004, veio a público a intenção de instalação do polo siderúrgico em parte da área demanda para a Resex, configurando-se um conflito cada vez mais intenso. No ano de 2005, desfez-se a possibilidade de criação do polo siderúrgico, mas as ações no Ibama do Maranhão, no sentido de criação da Resex, continuaram. No ano de 2006, foram concluídos os primeiros estudos e publicado o primeiro Laudo Socioeconômico e Biológico para a criação da Reserva Extrativista do Taim (IBAMA, 2006). Esse laudo passou por um processo de discussão nas comunidades e por uma Assembleia Pública para decidir sobre sua aprovação. Segundo Beto do Taim (entrevista realizada em 18/11/2015), um dos participantes sugeriu que as comunidades localizadas na ilha vizinha de Tauá-Mirim (Portinho, Jacamim, Ilha Pequena, Embaubau, Amapá e Tauá-Mirim) também fossem incluídas no perímetro da Resex, pois a ilha é bastante conservada e seus moradores mantêm um modo tradicional de vida. A proposta foi acatada e decidiu-se por consultar os moradores dessas comunidades e ampliar os estudos já realizados.

Uma rodada de consultas foi feita nas comunidades da ilha de Tauá-Mirim e os estu- 
dos foram ampliados para abrangê-las. No ano de 2007, o novo Laudo (IBAMA, 2007) estava pronto e, em nova Audiência Pública, decidiu-se pela criação da Resex. Os estudos e os resultados das oitivas foram enviados para o Ministério do Meio Ambiente. No ano de 2008, o Ministério solicitou que houvesse alteração do nome da Reserva, pois já existe uma Estação Ecológica no Rio Grande do Sul com esse nome. Após serem ouvidas as comunidades, decidiu-se por trocar o nome para Reserva Extrativista de Tauá-Mirim.

Nas Considerações Finais do Laudo enviado para o Ministério do Meio Ambiente, encontra-se a frase: "À luz dessas considerações e das informações sistematizadas neste laudo, conclui-se que a área em questão possui vocação ecológica e social para a consolidação de uma Reserva Extrativista”. Essa afirmação pode ser contrastada com a de planejadores governamentais e privados, que afirmam a vocação industrial da mesma área. São duas concepções opostas de natureza e de seu uso que se contrapõem e informam, diferentemente, os vários agentes sociais envolvidos em processos conflitivos.

Desde 2007, quando o processo foi enviado para o Ministério do Meio Ambiente, existe uma expectativa quanto à criação ou não da Reserva Extrativista de Tauá-Mirim. E. Em função da demora na criação, por provo: cação da União de Moradores do Taim, foram instaurados um Inquérito Civil Público pelo Ministério Público Federal, em 21/07/2008, e uma Ação Civil Pública pela Justiça Federal, que tramita desde 29/07/2013. O Governo do Estado do Maranhão e empreendimentos como Vale S. A. e Alumar têm colocado sérios óbices a à criação da Reserva, o que tem levado à sua î̀ procrastinação. O Governo Federal tem man-

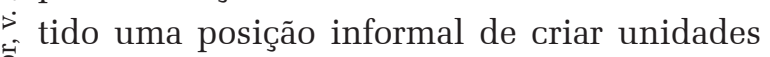
de conservação apenas com a aquiescência dos respectivos governos estaduais. Mesmo com a mudança no governo estadual, ocorrida no início de 2015, ao contrário da expectativa criada na maioria das lideranças envolvidas no processo da Reserva, não houve significativa alteração da posição governamental. O grupo político capitaneado pela Família Sarney, que governou o Maranhão de forma quase ininterrupta por mais de cinquenta anos e que tinha Roseana Sarney Murad (PMDB) com govenadora até o final de 2014, não conseguiu fazer sucessor e perdeu a eleição para Flávio Dino (PC do B), que fazia oposição ao grupo Sarney e contou com amplo apoio popular no processo eleitoral. No entanto, desde sua eleição, ele não se manifestou oficialmente de forma favorável à criação da Resex.

Durante todo esse período, as lideranças das comunidades e seus aliados têm procurado construir mecanismos de organização interna e de pressão sobre o Governo Federal para que a Reserva se efetive. Reuniões, assembleias, cursos de educação ambiental e criação de grupos de trabalho foram alguns dos mecanismos acionados. Porém, diante do adiamento permanente de qualquer posição mais definitiva, as lideranças das comunidades convocaram para o dia 17 de maio de 2015 mais uma Audiência Popular envolvendo as comunidades da Resex. A audiência foi precedida de um curso de formação política promovido pela Comissão Pastoral da Terra (CPT) e que envolveu membros de várias comunidades quilombolas, tradicionais e povos indígenas do interior do Maranhão. Nesse curso, um dos temas discutidos foi a autonomia das comunidades e seu protagonismo na tomada de decisões. Assim, a Assembleia Popular contou com a participação de vários representantes de outras comunidades e de movimentos populares e sindicais, além de religiosos e pesquisadores universitários.

Sem que houvesse um planejamento prévio e como decorrência dos debates ocorridos na Assembleia, e em encontros anteriores, os presentes decidiram que não seria mais possível esperar uma decisão oficial do Governo e, numa atitude de desobediência civil, decretaram criada, se não de direito, mas de fato, a Reserva Extrativista de Tauá-Mirim. Na mesma oportunidade, foi criado o Conselho Gestor da Resex, com 
a missão de realizar a permanente mobilização da Reserva, de pensar um plano de manejo e de continuar a luta pela sua oficialização.

Um dos desafios enfrentados pelo Conselho Gestor durante o ano de 2015 foi a tentativa da Prefeitura Municipal de São Luís de promover uma alteração no Plano Diretor e fazer uma revisão completa da Lei de Zoneamento, Parcelamento, Uso e Ocupação do Solo do município. O estudo da proposta inicial apresentada pela Prefeitura demonstrou que, mais uma vez, havia uma tentativa de converter boa parte da Zona Rural de São Luís em Zona Industrial ou Portuária. Essa conversão comprometeria fortemente a demanda pela oficialização de Resex, pois parte de seu território deixaria de ser zona rural. Mais uma vez, o repertório contencioso foi acionado e novos arranjos de alianças foram construídos para tentar interferir no processo de discussão pública da legislação urbanística. Buscando aliar os interesses dos defensores da Resex com outros grupos que contestavam aspectos diferenciados da proposta da Prefeitura, foi constituído o Movimento de Defesa da Ilha, prestando, assim, homenagens ao Comitê de Defesa da Ilha e ao Movimento Reage São Luís, que atuaram em outros momentos históricos.

Até o momento em que este artigo estava sendo escrito, a mobilização popular e a reunião de argumentos originários de vários campos do conhecimento têm conseguido impedir o necessário prosseguimento das audiências públicas convocadas pela Prefeitura, principalmente, pela alegação da falta de publicidade adequada e pela sua indevida condução, pois não permitem o cumprimento da exigência legal de ampla participação de todos os interessados. Além desses argumentos, constatou-se que a Prefeitura optou por fazer a revisão de uma parte do Plano Diretor em conjunto com a revisão da Lei de Zoneamento, o que também é uma irregularidade, pois a segunda somente pode entrar em discussão após a vigência do primeiro. Atendendo à provocação de membros do Conselho da Cidade e do
Movimento de Defesa da Ilha, o Ministério Público do Maranhão recomendou a suspensão de todo processo e que, respeitando os princípios da publicidade e da participação popular, primeiro se faça o processo de revisão do Plano Diretor e depois seja encaminhada a discussão da Lei de Zoneamento. Esse é um processo que está em andamento, mas que vem sendo considerado pelas lideranças da Resex como mais uma conquista e como fator que pode contribuir para sua legalização, pois a mobilização popular conseguiu alterar o calendário da Prefeitura e dos principais interessados na aprovação rápida e sem ampla discussão das referidas leis.

\section{EM BUSCA DE CONCLUSÕES OU DE ABERTURAS DE POSSIBILIDA- DES}

A lógica de ocupação e de uso do espaço que tem orientado planejadores e agentes de desenvolvimento estatais e privados em São Luís desqualifica modos de vida de comunidades tradicionais cujas principais lideranças, na busca de manter seu território, acionam repertórios de luta e constroem mecanismos de enfrentamento.

Orientados por uma concepção de desenvolvimento que transforma São Luís em um corredor de exportação ou de produção voltada para o mercado externo, planejadores governamentais e privados operam com usos seletivos de territórios, que excluem comunidades, alteram modos de vida e comprometem a conservação ambiental. Como resultado mais palpável, segundo dados do IBGE (2016), a cidade de São Luís é detentora do $15^{\circ}$ Produto Interno Bruto Municipal (PIBM) do Brasil, e o Maranhão detém o $16^{\circ}$ Produto Interno Bruto (PIB) entre os estados. Esses signos de crescimento econômico (mesmo em momento de uma crise econômica no país), não correspondem a uma efetiva melhoria de vida população da cidade e do estado. Ao lado de números ex- 
pressivos do crescimento econômico, encontra-se a permanência de índices vergonhosos do chamado desenvolvimento humano. Altos índices de migração, de trabalho escravo e de pobreza demonstram que, entre desenvolvimento econômico e melhoria da qualidade de vida, não existe uma correlação necessária.

A luta por manter o controle do território por parte de comunidades tradicionais é também a luta para não permitir que o avanço do desenvolvimento funcione como rolo compressor, relegando seus moradores para processos de periferização e, portanto, de ampliação da miséria. A manutenção dos territórios significa a manutenção da dignidade e o combate à ampliação de injustiças sociais e ambientais.

Encerramos este artigo com um depoimento escrito em maio de 2011 por D. Maria Máxima Pires, da comunidade do Rio dos Cachorros que, a partir de intensos confrontos com projetos de expansão industrial e portuária no município de São Luís, Maranhão, revela seus sentimentos com relação ao território que ocupa e sua compreensão das lógicas que se confrontam em torno dele:

Se você me perguntasse antes sobre meio ambiente, não saberia lhe dizer nada, porque para mim e algumas pessoas de comunidade (conversamos sobre tudo) "meio ambiente" é também um termo novo,

criado para nós, apenas para nos tirar a atenção de dizer que a "natureza”, que é de fato com quem nós temos intimidade, estava sendo destruída. Para as comunidades, ainda continua assim: "a natureza e o homem", um pertencendo, respeitando o outro. Sentimento, permissão e advertência: foi assim que nós aprendemos com os nossos avós, pais. Não precisava ter serviços de meteorologia para saber se ia chover ou não, não precisava de técnicos para fazer correção no solo, porque eles sabiam onde o terreno estava mais fértil, não precisava recorrer à Secretaria de Meio Ambiente para dizer que a área estava sendo destruída, porque eles já sabiam disso. E o que mais nos admira é que eles nos ensinaram que a terra é a nossa mãe, e, mesmo quando precisam "queimar" para fazer o roçado, para plantar mandioca, milho, vinagreira etc., [...] eles pediam “permissão" e hoje eu entendo tudo isso, porque, como uma verdadeira mãe, ela estava sempre perdoando e nos alimentando. E como uma mãe é capaz de dar sua última gota de sangue para seus filhos, para nós e para ela (terra), um pertence ao outro, um não vive sem o outro, e esse sentimento de pertencimento não interessa às multinacionais e empresas que devastam tudo a favor do seu próprio lucro (grifos no original).

Recebido para publicação em 21 de janeiro de 2016 Aceito em 23 de abril de 2016

\section{REFERÊNCIAS}

ACSELRAD, Henri. As práticas espaciais e o campo dos conflitos ambientais. In: ACSELRAD, Henri (Org.). Conflitos ambientais no Brasil. Rio de Janeiro: Relume Dumará: Fundação Heinrich Böll, 2004. p. 13-35.

ADRIANCE, Madelaine Cousineau. Terra prometida: as comunidades eclesiais de base e os conflitos rurais. São Paulo: Paulinas, 1996.

ALMEIDA, Alfredo Wagner Berno de. Refugiados do desenvolvimento: os deslocamentos compulsórios de índios e camponeses e a ideologia da modernização. Travessia, Florianópolis, p. 30-35, maio/ago. 1996.

ALUMAR. Alumar: Compromisso com o desenvolvimento sustentável. 2010. Disponível em: http://www.alumar. com.br. Acesso em: 21 fev. 2016.

ALVES, Elio de Jesus Pantoja. Repertórios e argumentos da mobilização política: um estudo sobre o Movimento Reage São Luís, em São Luís - MA. 2014. 190f. Tese (Doutorado em Sociologia) - Instituto de Filosofia e Ciências Sociais, Universidade Federal do Rio de Janeiro, Rio de Janeiro, 2014. ; SANT'ANA JÚNIOR, Horácio Antunes; MENDÓNÇA, Bartolomeu Rodrigues. Projetos de Desenvolvimento, Impactos Sócio-Ambientais e a Reserva Extrativista do Taim. In: Ciências Humanas em Revista. Universidade Federal do Maranhão, Centro de Ciências Humanas. São Luís, 2007. v. 5 Número Especial. Semestral. p. 29-40.

AYRES, Érico de Oliveira Junqueira. Parâmetros para a localização de áreas e distritos industriais, com objetivo de avaliação dos impactos sobre a estrutura urbana. 1990. Dissertação (Mestrado em Arquitetura e Urbanismo) - da Universidade de São Paulo, São Paulo, 1990.

BRASIL. Lei $n^{\circ}$ 9.985, de 18 de julho de 2000. Regulamenta $\mathrm{o}$ art. 225, § 10, incisos I, II, III e VII da Constituição Federal, institui o Sistema Nacional de Unidades de conservação da natureza e dá outras providências. Diário Oficial [da] República Federativa do Brasil, Poder Executivo, Brasília, DF. 14 jul. 2000. Disponível em: http://www.planalto.gov. br/ccivil_03/leis/L9985.htm. Acesso em: 21 mar. 2016.

. Decreto $\mathrm{n}^{\circ} 6.040$, de 07 de fevereiro de 2007. Institui a política Nacional de desenvolvimento sustentável dos povos e comunidades tradicionais. 2007. . Disponível em http://www.planalto.gov.br/ccivil_03/_ato2007-2010/2007/ decreto/d6040.htm. Acesso em: $2 \overline{1}$ mār. 2016.

CÂNDIDO, Antônio. Os parceiros do Rio Bonito: estudo sobre o caipira paulista e a transformação dos seus meios de vida. São Paulo: Duas Cidades, 1975.

CARNEIRO, Marcelo D. S. Do latifúndio agropecuário à empresa latifundiária carvoeira. In: COELHO, M. C. N. e COTA, R. G. (Orgs.). 10 anos da Estrada de Ferro Carajás. Belém: UFPA/NAEA, 1997. p. 223-250.

. Estado e empreendimentos guseiros no Programa 
Grande Carajás. In: CASTRO Edna Maria Ramos de; MARIN, Rosa Elizabeth Azevedo. (Org.). Amazônias em tempo de transição. Belém: UFPA, 1989. p. 151-192.

CARVALHO, Fernanda Cunha de. Ordenamento territorial e impactos sócio-ambientais no distrito industrial de São Luís - MA. 2008. Trabalho de Conclusão de Curso (Graduação em Geografia) - Universidade Federal do Maranhão, [S.l.], 2008.

$$
\text { Ordenamento territorial e impactos }
$$
socioambientais no Distrito Industrial de São Luís-MA. In: SANT'ANA JÚNIOR, Horácio de Antunes et al. (Org.). Ecos dos conflitos socioambientais: a Resex de Tauá-Mirim. São Luís EDUFMA, 2009.

$$
\text { Gestão do território, lugar e conflitos }
$$
socioambientais: o caso da usina termelétrica Porto de Itaqui em São Luís. 2011. 121 f. Dissertação (Mestrado em Geografia) - Departamento de Geografia, Universidade de Brasília, Brasília, 2011.

EGLISH, Ann Bárbara. Alcoa na Ilha: um documento acerca das implicações sociais, econômicas e ambientais da implantação de uma indústria de alumínio em São Luís do Maranhão. São Luís: Cáritas Brasileira, 1984.

GISTELINK, Frans. Carajás, usinas e favelas. São Luís: [S.n.], 1988.

INSTITUTO BRASILEIRO DE GEOGRAFIA E ESTATÍSTICA (IBGE). Maranhão - São Luís.. 2010. Disponível em: http://cidades.ibge.gov.br/xtras/perfil. php?codmun=211130. Acesso em: 21 mar. 2016.

INSTITUTO BRASILEIRO DO MEIO AMBIENTE E DOS RECURSOS NATURAIS RENOVÁVEIS (IBAMA). Laudo sócio-econômico e biológico para a criação da reserva extrativista do taim. São Luís: [S.n.], 2006. Mimeografado.

. Laudos sócio-econômico e biológico para a criação da reserva extrativista do taim. São Luís: [S.n.], 2007. Mimeografado.

LOPES, José S. Leite. A ambientalização dos conflitos sociais: participação e controle público da poluição industrial. Rio de Janeiro: Relume Dumará, 2004.

MAGALHÃES, S. Barbosa. Lamento e dor: uma análise sócioantropológica do deslocamento compulsório provocado pela construção de barragens. 2007. 279 f. Tese (Doutorado em Ciências Sociais) - Instituto de Filosofia e Ciências Humanas, Universidade Federal do Pará, Belém, 2007.

MARANHÃO. O Maranhão e a nova década: oportunidade e desafios. São Luís: Governo do Estado do Maranhão, Secretaria Estadual de Planejamento, 2010.

MIRANDA, Ana Caroline Pires; MAIA, Maiana Roque da Silva; GASPAR, Rafael Bezerra. Entrevista com Alberto Catanhede, o Beto do Taim. In: SANT’ANA JÚNIOR,
Horácio de Antunes et al. (Org.). Ecos dos conflitos socioambientais: a Resex de Tauá-Mirim. São Luís: EDUFMA, 2009. p. 177-204.

MONTEIRO, Maurílio. A siderurgia e a produção de carvão vegetal no corredor da Estrada de Ferro Carajás. In COELHO, M. C. N.; COTA, R. G. (Org.). 10 anos da Estrada de Ferro Carajás. Belém: UFPA: NAEA, 1997. p. 183-222.

MOREIRA, Jadeylson Ferreira. Arenas, repertórios e acões: o processo de tentativa de implantação do Terminal Portuário de São Luís, no povoado Cajueiro. 2015. 143 p. Dissertação (Mestrado em Ciências Sociais) - Centro de Ciências Humanas, Universidade Federal do Maranhão, São Luís, 2015.

OLIVEIRA, Josemiro Ferreira de. Arraial do furo (Vila Maranhão): uma perspectiva histórica. 2016. 59 p. Trabalho de Conclusão de Curso (Graduacão em Ciências Sociais) - Universidade Federal do Maranhão, [S.l.], 2016.

SANT'ANA JÚNIOR, Horácio Antunes. Florestania: a saga acreana e os Povos da Floresta. Rio Branco-AC: EDUFAC, 2004.

Carajás 30 anos: projetos de desenvolvimento, resistências e mobilizações na Amazônia oriental. Vias de fato, São Luís, p. 6-7, ago. 2013. Disponível em: http:// www.viasdefato.jor.br. Acessado em: 20 jan. 2016.

Projetos de desenvolvimento e a criação de reservas extrativistas: estratégias de luta de grupos sociais locais no Acre e no Maranhão. In: ESTERCI, Neide; SANT'ANA JÚNIOR, Horácio Antunes de.; TEISSERENC, Maria José da Silva Aquino (Org.). Territórios socioambientais em construção na Amazônia brasileira. Rio de Janeiro: 7 Letras, 2013.

; PEREIRA, Carla Regina Assunção; ALVES, Elio de Jesus Pantoja. Projetos de desenvolvimento e conflitos socioambientais no maranhão. Teoria e sociedade, Belo Horizonte, n. 18.1, p. 94-113, jan./jun. 2010.

et al. A RESEX de Tauá-Mirim, grandes projetos de desenvolvimento e a resistência socioambiental: introduzindo o debate. In: SANT'ANA JÚNIOR, Horácio de Antunes et al. (Org.). Ecos dos conflitos socioambientais: a Resex de Tauá-Mirim. São Luís: EDUFMA, 2009.

SOUSA, Alan de Andrade. O ambiente, a política, o espetáculo: a Lei de Zoneamento e o projeto do polo siderúrgico de São Luís. In: SANT’ANA JÚNIOR, Horácio de Antunes et al. (Org.). Ecos dos conflitos socioambientais: a RESEX de Tauá-Mirim. São Luís: EDUFMA, 2009. p. 6186.

TILLY, C. From mobilization to revolution. Boston: Wesley Publishing Co., 1978.

Coerção, capital e rstados europeus: 1990-1992. São Paulo, EDUSP, 1996. 


\section{PORT COMPLEX, EXTRACTIVE RESERVE AND DEVELOPMENT IN MARANHÃO}

Horácio Antunes de San’Ana Júnior

In São Luís-MA, development projects imply in expanding of the Port Complex and conflicts with traditional communities that demand the legalization of the Reserva Extrativista de TauáMirim. Face territorial occupation and conceptions of nature differents logics, in an environmental conflict with new contours with projects of expansion of infrastructure and industrial equipment and modifications in the urban legislation. Therefore, the goal here is to analyse how development concepts that guide the various agents cause social and environmental consequences unfold in situations of conflicts. This article part of research work realized for ten years, through bibliographical survey, interviews, informal conversations, followup assemblies, meetings, public audiences, and public manifestations. The logic of occupation and use of the space that has guided planners and State and private development agents in São Luís disqualifies lifestyles of rural communities whose main leaders, in seeking to maintain their territory, fighting repertoire and build face mechanisms.

KeYwORDS: Keywords: Environmental Conflict. Development Projects. Port Complex of São Luís. Reserva Extrativista de Tauá-Mirim. Urban Legislation. graduação em Ciências Sociais e Políticas Públicas da Universidade Federal do Maranhão. Líder do Grupo de Estudos: Desenvolvimento, Modernidade e Meio Ambiente. Entre as principais publicações estão os livros: Florestania: a saga acreana e os Povos da Floresta (publicado pela EDUFAC, em 2004); Territórios socioambientais em construção na Amazônia brasileira (organizado em conjunto com Neide Esterci e Maria José da Silva Aquino Teisserenc e publicado pela 7 Letras em 2014); Trabalho Escravo Contemporâneo: um debate transdisciplinar (organizado em conjunto com Ricardo Rezende Figueira e Adônia Antunes Prado pela Mauad em 2011) e Ecos dos conflitos socioambientais: a Resex de TauáMirim (organizado em conjunto com Madian de Jesus Frazão Pereira, Elio de Jesus Pantoja Alves e Carla Regina Assunção Pereira e publicado pela EDUFMA em 2009).
En São Luís-MA, projets de développement impliquent dans l'expansion du complexe traditionnelles qui demandent la légalisation de la Reserva Extrativista de Tauá-Mirim. Visage différentes logiques de occupation territoriale et des conceptions de la nature, dans un conflit environnemental prend nouveaux contours avec des projets d'expansion des infrastructures et des équipements industriels et de modifications dans la législation urbanistique. Le but ici est donc d'analyser comment les concepts de développement qui guident les divers agents causent conséquences sociales et environnementales et se déroulent dans des situations des conflits. Le article partie de travail de recherche realisé pendant dix ans, au moyen d'une enquête bibliographique, mener des entrevues, des conversations informelles, réunions, suivies assemblées, des audiences publiques, et manifestations publiques. La logique d'occupation et d'utilisation de l'espace qui a guidé les planificateurs et les agents de développement de le Stat et privé au São Luís disqualifier des modes de vie des communautés rurales dont les principaux dirigeants, en cherchant à maintenir leur territoire, gargette répertoire de combat et construire des mécanismes de faire face. Développement. Complexe Portuaire de São Luís. Reserva Extrativista de Tauá-Mirim. Législation Urbanistique. portuaire et les conflits avec les communautés

Mots-clés: Conflit Environnemental. Projets de 